\title{
Ethical aspects of registry-based research in the Nordic countries
}

This article was published in the following Dove Press journal:

Clinical Epidemiology

23 November 2015

Number of times this article has been viewed

\author{
Jonas F Ludvigsson ${ }^{1,2}$ \\ Siri E Håberg ${ }^{3}$ \\ Gun Peggy Knudsen ${ }^{3}$ \\ Pierre Lafolie ${ }^{4,5}$ \\ Helga Zoega ${ }^{6}$ \\ Catharina Sarkkola ${ }^{7}$ \\ Stephanie von $\mathrm{Kraemer}^{7}$ \\ Elisabete Weiderpass ${ }^{1,7-10}$ \\ Mette Nørgaard"' \\ 'Department of Medical Epidemiology \\ and Biostatistics, Karolinska Institutet, \\ Stockholm, ${ }^{2}$ Department of Pediatrics, \\ Örebro University Hospital, Örebro, \\ Sweden; ${ }^{3}$ Norwegian Institute \\ of Public Health, Oslo, Norway; \\ ${ }^{4}$ Department of Medicine, Clinical \\ Pharmacology Unit, ${ }^{5}$ The Stockholm \\ Regional Ethical Review Board, \\ Karolinska Institutet, Stockholm, \\ Sweden; ${ }^{6}$ Center of Public Health \\ Sciences, Faculty of Medicine, \\ University of Iceland, Reykjavík, \\ Iceland; ${ }^{7}$ Genetic Epidemiology \\ Group, Folkhälsan Research Center, \\ Helsinki, Finland; ${ }^{8}$ Department of \\ Community Medicine, Faculty of \\ Health Sciences, University of Tromsø, \\ ${ }^{9} T$ The Arctic University of Norway, \\ Tromsø, ${ }^{10}$ Department of Research, \\ Cancer Registry of Norway, Oslo, \\ Norway; "Department of Clinical \\ Epidemiology, Aarhus University \\ Hospital, Aarhus, Denmark
}

Correspondence: Jonas F Ludvigsson Department of Medical Epidemiology and Biostatistics, Karolinska Institutet, Solnavägen I, I7I77 Solna, Stockholm, Sweden

$\mathrm{Tel}+46852480000$

Fax +4608314975

Email jonasludvigsson@yahoo.com
Abstract: National health care registries in the Nordic countries share many attributes, but different legal and ethical frameworks represent a challenge to promoting effective joint research. Internationally, there is a lack of knowledge about how ethical matters are considered in Nordic registry-based research, and a lack of knowledge about how Nordic ethics committees operate and what is needed to obtain an approval. In this paper, we review ethical aspects of registry-based research, the legal framework, the role of ethics review boards in the Nordic countries, and the structure of the ethics application. We discuss the role of informed consent in registry-based research and how to safeguard the integrity of study participants, including vulnerable subjects and children. Our review also provides information on the different government agencies that contribute registry-based data, and a list of the major health registries in Denmark, Finland, Iceland, Norway, and Sweden. Both ethical values and conditions for registry-based research are similar in the Nordic countries. While Denmark, Finland, Iceland, Norway, and Sweden have chosen different legal frameworks, these differences can be resolved through mutual recognition of ethical applications and by harmonizing the different systems, likely leading to increased collaboration and enlarged studies.

Keywords: ethical review, ethics, institutional review board, Nordic countries, registry-based research, informed consent

\section{Introduction}

National population-based registries (Table S1), virtually free health care ${ }^{1}$ (costs are covered through the tax bill), a high degree of public trust in research, ${ }^{2}$ plus the belief in social equality and mutual responsibility and the existence of personal identity numbers (PINs) allowing unambiguous linkage of large-scale data ${ }^{3,4}$ all contribute to the success of epidemiological research in the Nordic countries (Denmark, Finland, Iceland, Norway, and Sweden). A mandatory prerequisite for continued use of national health care data for medical research is, however, that the personal integrity of participating individuals is guaranteed.

Population-based registry data have been extensively used to examine a number of important areas in which other study designs may be unethical or difficult to use, including the association between type 1 diabetes and other autoimmune diseases, ${ }^{5}$ the recurrence of preeclampsia, ${ }^{6}$ the association between birth characteristics and later cardiovascular disease, ${ }^{7}$ substance abuse, and the risk of psychotic disorders in epilepsy, ${ }^{8}$ as well as the risk of fetal death following maternal vaccination against influenza. ${ }^{9}$

While a similar cultural background and a history of collaboration in the Nordic countries encourage multilateral research projects, differences in legal and ethical 
frameworks represent obstacles for collaborative initiatives. The aim of the current work was to review ethical aspects of registry-based research, the ethics application (EA), and the role of ethics committees (ECs) in the Nordic countries. Currently, approval from each national EC in the Nordic countries is needed to conduct trans-Nordic research.

\section{The EC}

\section{Organization and election of members}

Before a medical project is initiated, approval from an EC is required. ECs (also called "ethics review boards", "ethics vetting boards", or "institutional review boards" [IRBs]) are made up of both professional and lay representatives (Table 1). Members of the EC are usually appointed by academic or research institutions or by the government. Table 1 gives an overview of the ECs in the Nordic countries. Greenland follows the Danish legislation, and their ethical committee follows the practices of the Danish ethical committee system. In Faroe Islands, the legislation is also similar to that of Denmark, and The Faroese Committee on Biomedical Research Ethics generally follows the practices of the Danish ethical committee system.

With the exception of Iceland, ECs in all Nordic countries are regional. The geographic responsibility of each EC often coincides with that of a specific health care region, but that does not necessarily imply that the EC per se is linked to a specific hospital. For instance, the largest EC in Sweden is "the EC in Stockholm" and not "the EC of Karolinska Institutet".

\section{The central EC}

Decisions in a regional EC can be appealed to the central EC. Appeals are uncommon for registry-based research in that ECs tend to see that the advantages of the research outweigh the disadvantages (and therefore approve most EAs). ${ }^{10}$

The central EC of Sweden considers appeals from researchers whose applications to a regional EC have been rejected. Furthermore, the central EC of Sweden supervises and ensures that relevant laws and regulations (Law 2003:640, $\S 34)$ are strictly followed. ${ }^{11}$ The central EC in Sweden also investigates potential scientific misconduct.

In Finland, there is one central EC, the National Committee on Medical Research Ethics, which belongs to the National Supervisory Authority for Welfare and Health (Valvira), which, in turn, operates under The Ministry of Social Affairs and Health. The role of the committee is to support and coordinate activities of the regional ECs concerning the processes of the statements/opinions as well as principled research ethical questions. In addition, the committee gives national statements/opinions on clinical drug trials, unless the statements/opinions have been relinquished to a regional EC. The central EC also reviews and gives an opinion to the regional EC when a regional EA has been rejected. In these cases, the central EC reviews the application in its original version.

The central committee also participates in international collaboration on research regarding ethical issues. The committee collects and mediates information about issues in research and mediates information about international ethical discussions through such venues as publications and training occasions. Finally, the committee promotes a national discussion about medical and biomedical research. ${ }^{12}$

In Iceland, there is one central EC, the National Bioethics Committee, which evaluates collaborative projects, multinational projects, clinical trials of medicinal products, and other prospective scientific research projects in the health sector. ${ }^{13}$ Additionally, there are the Health Research Ethics Committees maintained at two major hospitals, the Landspítali University Hospital, Reykjavík, Iceland, and the Akureyri Hospital, Akureyri, Iceland for research projects in the health sector to be carried out at these institutions. All applications concerning clinical trials and international cooperation are, however, submitted to the central National Bioethics Committee. The ECs in Iceland forward a list of all applications to the Data Protection Authority for review, and in some cases, further approval of research pertaining to protection of individual privacy and security of data processing.

In Denmark, there is one central EC, The National Committee on Health Research Ethics (DNVK). In addition to acting as board of appeal in connection with decisions made in the regional ECs, the DNVK coordinates activities in the regional committees, writes guidelines, gives opinions on issues of a fundamental nature (if these opinions are not related to the approval of a concrete research project), monitors the development of research within the health sector, and promotes the understanding of ethical problems resulting from this development. Finally, the DNVK makes recommendations to the Minister of the Interior and Health and provides consultative statements on biomedical research projects planned by Danish researchers for implementation in developing countries.

In Norway, the National Committee for Medical and Health Research Ethics (NEM) coordinates the seven regional ECs for medical and health research. The National Committee for Research Ethics in the Social Sciences and Humanities and the National Committee for Research Ethics in Science and Technology are National ECs that draw up guidelines and provide advice to individual projects within 


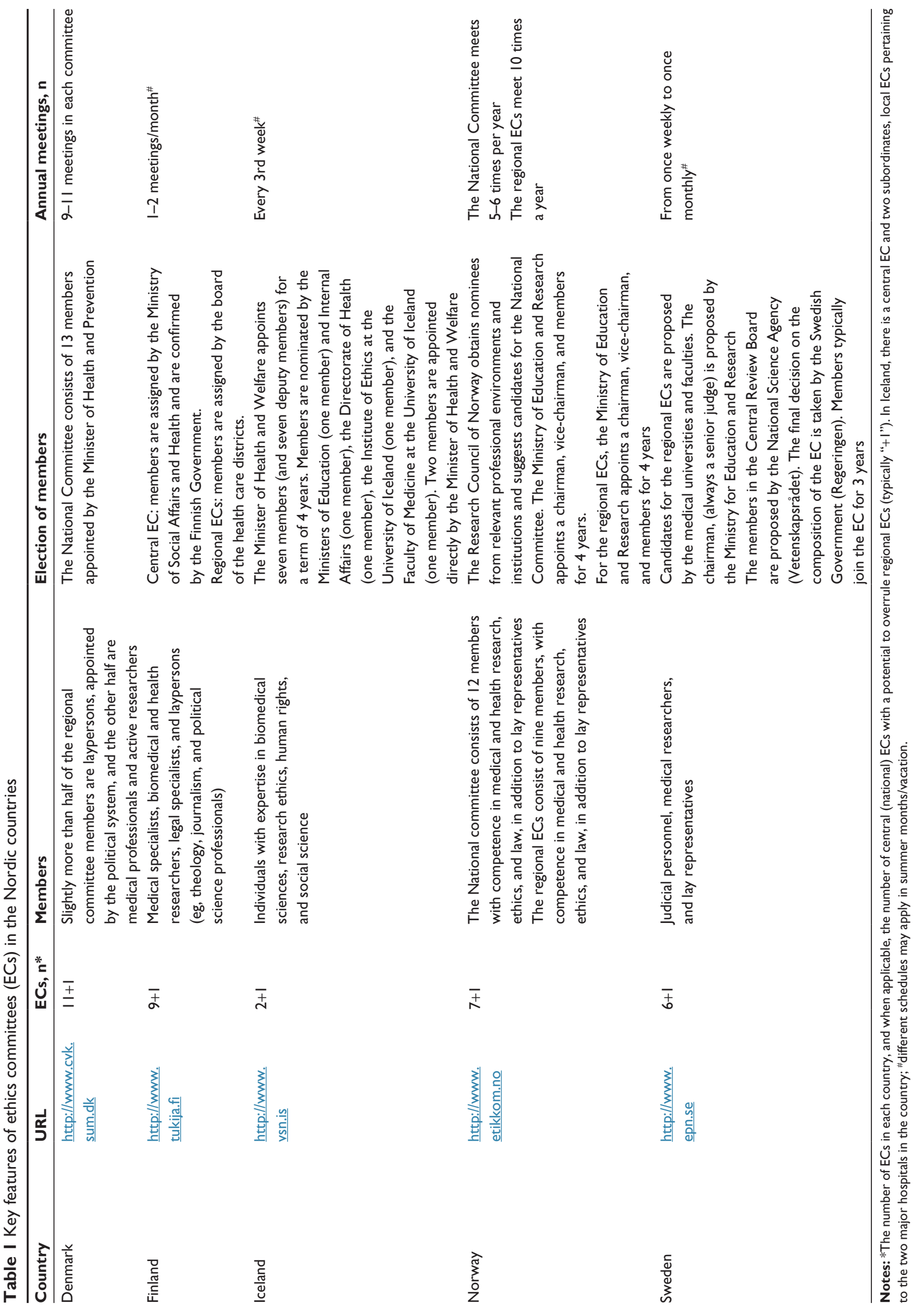


their fields. The National Commission for the Investigation of Research Misconduct may investigate allegations and suspicions of misconduct in research, and the National Committee for Research Ethics on Human Remains evaluates the ethical aspects of research in which the source material consists of human remains from museums, collections, and archeological excavations. NEM was set up in 1990 and serves as an advisory and place of appeal for the seven regional ECs. NEM offers its opinion on issues that are a matter of principle, prepares guidelines and reports, and organizes open discussion forums on various ethical topics related to research. The national committees meet biannually to coordinate relevant issues. All members of NEM and the regional ECs attend an annual joint meeting for professional discussion.

\section{Time-limited validity of EAs}

As opposed to approvals from, for instance, the American IRBs,${ }^{14}$ the validity of the approvals of Swedish ECs is not time-limited (and hence no annual approval is needed), but an approved project must start within 2 years from the date of approval. ${ }^{15}$ For projects with funding from the US National Institutes of Health (NIH), Swedish ECs may sometimes certify that annual ethics approvals are not needed according to Swedish law.

In Finland, a re-approval is needed when there is a change, addition, or update concerning the project and research plan, from an ethical point of view. ${ }^{16}$ Finnish researchers must also state a starting and ending date in the application form. In Iceland, the approval is time-limited, depending on each project and application. ${ }^{17}$ After that, a re-approval, or an amendment in case of deviations from the original study protocol, is required to carry on the research. In Denmark, the approval from the EC covers the project as it is described in the application, and no annual re-approvals are necessary. ${ }^{18}$ In case of deviations from the approved protocol (eg, inclusion of new biomarkers or prolongation of the study period), an amendment to the original protocol must be approved. For registry-based research, only projects that incorporate biological material require an EC approval, so most Danish registry-based studies are covered by an approval from the Danish Data Protection Agency. These latter approvals cover a specified period (eg, 5 or 10 years) and must be re-approved after the fixed period.

In Norway, the ECs approve the projects with a set start and end date of the project (typically 5 years). The projects do not report annually to the ECs, but must apply for a re-approval whenever a change occurs in the project (eg, new project members, changes in aims or data collection, or prolongation of the study period). Since July 1, 2009, Norwegian researchers must also submit a report to the EC at the end of the project (ACT 2008-06-20 number 44, chapter 4, $\S 12$ ). For projects including data from the prescription database, an approval from the Norwegian Data Protection Agency is mandatory.

\section{The EA}

In this section, we describe an EA, but with special focus on those parts that are of particular relevance to registry-based research. Project-specific information (such as title, scientific background, hypothesis, and methods) is not treated in this paper.

\section{The applicant}

In all Nordic countries except Sweden, the principal investigator (PI) is the main applicant of the EA (the only exception being student projects in which case, the student supervisor is the applicant) (Table 2). Usually, the PI is also the guarantor of the study. ${ }^{16}$ In Sweden, the PIs are the contact persons, but

Table 2 Content of ethics application (EA)

\begin{tabular}{|c|c|c|c|c|c|c|}
\hline \multirow[t]{2}{*}{ Country } & \multirow{2}{*}{$\begin{array}{l}\text { Someone other } \\
\text { than the principal } \\
\text { investigator (PI) } \\
\text { needs to sign the EA }\end{array}$} & \multirow[t]{2}{*}{ Data key $\infty$} & \multicolumn{4}{|c|}{ Must be discussed and reported in the EA } \\
\hline & & & $\begin{array}{l}\text { How to store } \\
\text { personal data }\end{array}$ & Power calculation $^{\#}$ & Informed consent & $\begin{array}{l}\text { Relationship between } \\
\text { the researcher and } \\
\text { the research subject }\end{array}$ \\
\hline Denmark ${ }^{\#}$ & No & Yes & No & Yes & Yes & No \\
\hline Finland & No & Yes & Yes & Yes & Yes & Yes \\
\hline Iceland & No & Yes & Yes & No & Yes & Yes \\
\hline Norway & Yes* & Yes** & Yes & Yes & Yes & Yes \\
\hline Sweden & Yes, head of department $* * *$ & Yes & Yes & Yes & Yes & Yes \\
\hline
\end{tabular}

Notes: *In Norway, according to the Health Research Act, medical and health research must be organized as a project under the direction of a person or body responsible for the research. Typically, this will be at an institutional level, and as such, the head of the department, division, or section needs to approve the application; **some data owners and registries, such as the Norwegian Prescription Registry, do not allow that a key is preserved between a person's personal identity number (PIN) and the research identifier; ***to eliminate projects without basic resources, the head of the department must sign the EA to guarantee that the responsible researcher has access to I) resources adequate to finish the project and 2) a physical workplace from where the project can be conducted; "the EC requests a power calculation. This calculation ensures that the study does not waste resources (ie, is unethical) and do not waste study participants' time without being able to answer the main research question; "\#in the case of multi-center trials, the investigator should only apply for permission from the regional committee in the area, where the PI carries out the research project; ${ }^{\circ}$ key between PINs and data can be preserved; ;in Denmark, the researchers usually have PINs included in the delivered dataset. 
their responsible body (usually the university where they are affiliated) is the applicant.

The first part of the EA deals with the involved researchers and the research body they represent. The research body is often the researcher's employer. Typical research bodies include universities, certain government agencies, private research institutes, certain foundations, and county councils. While the EA must contain a short scientific background, this part should typically focus on expected knowledge gains and the (clinical) importance of the proposed research. In Sweden, Finland, Denmark, and Norway, the ECs require researchers to attach separate information for laypersons about the project at submission. Swedish ECs stipulate that all information be given in Swedish, but in reality, the appended research plan may be written in English.

Researchers are expected to outline the data collection process in detail and how they plan to monitor data quality. Most registry-based research will not 1) deviate from clinical routine; or even 2) involve direct contact with the study participants. Hence, no personal consent is needed from the study participants to obtain approval from the ECs.

As part of the description of the data collection, the sources of data (eg, the Cause of Death Registry) and data storage should also be described. Typically, the researcher must guarantee that collected data are stored without nonresearchers having access to confidential data. In exceptional cases, the government agencies responsible for collection and storage of national health care data (Table 3 ) will supply a researcher with identifiable data (more common in Denmark than elsewhere [Table 2]), but most often data are distributed pseudonymized. True anonymization implies that there is no key between the identity of an individual (his/her PIN) and the data used by the researcher (where individual study participants are usually differentiated by serial numbers). Anonymization precludes any additional linkage or clarification of improbable data and is, therefore, not ideal in registrybased research. Pseudonymization means that there is a key and an opportunity to define the true identity of individuals in a dataset, and eg, to link these individuals to new data if needed or to update their medical history.

In addition, in Finland, researchers will receive data with full identification in those cases when the participants have consented to the study and have released their PIN themselves. However, there are some exceptions, depending on the registry. For example, data from social welfare registries never include PINs; instead, data is pseudonymized. The same applies to registry-based research without consent.
With pseudonymized data, researchers may request that a key file (between the PIN and the serial number) be stored at the government agency responsible for the data matching (applicable in Sweden, Finland, Norway, and Iceland). There is international variation; for instance, the key file can generally be kept for 1-3 years in Sweden but can be kept for 5 years in Finland (thereafter, a re-approval is needed), or must be destroyed immediately upon linkage (eg, for some studies in Iceland). The key file allows the government agency to re-match if the researchers detect errors in the dataset, but the key file also allows the researchers to request additional matching of data to their original dataset (after approval by the EC). An exception to the rule not to deliver identifiable data is the validation of diagnoses and procedures in the national health care registries. For validation purposes, the EC grants the researchers access to the PINs of a list of patients in order to request certain information (eg, patient charts for validation purposes).

\section{Storage of data}

Researchers must describe how collected data will be stored, who (which persons) will have access to the data, and for how long the data will be kept (with or without the PIN, and where potential coding lists are stored) (Table 2). ${ }^{19}$ In most registry-based projects, the applicant states that no procedures or extra data collection will be performed, that recording of data is carried out as part of routine health care (provided the researcher uses only data from the national health care registries), that the researchers will not have access to coding lists (if existing, the lists will be stored at the relevant government agency), and that data used for analyses are pseudonymized or anonymized. Biological samples obtained for research purposes must immediately be transferred to a biobank.

\section{Biobanks}

National laws in all Nordic countries, except Denmark, stipulate that the establishment of a new biobank must be registered at the National Board of Health and Welfare (Finland, 688/2012; Iceland, 110/2000; Norway, LOV-2003-02-21-12 for treatment and diagnostic biobanks and LOV-2008-0620-44 for research biobanks; and Sweden, 2002:297). Before a biobank is created in Finland, it must also be registered in the national biobank registry. Registration is done through a notice to the National Supervisory Authority for Welfare and Health (Valvira). The establishment of a new biobank must be authorized by the Minister of Health and Welfare and must be approved by the Directorate of Health, the Data 


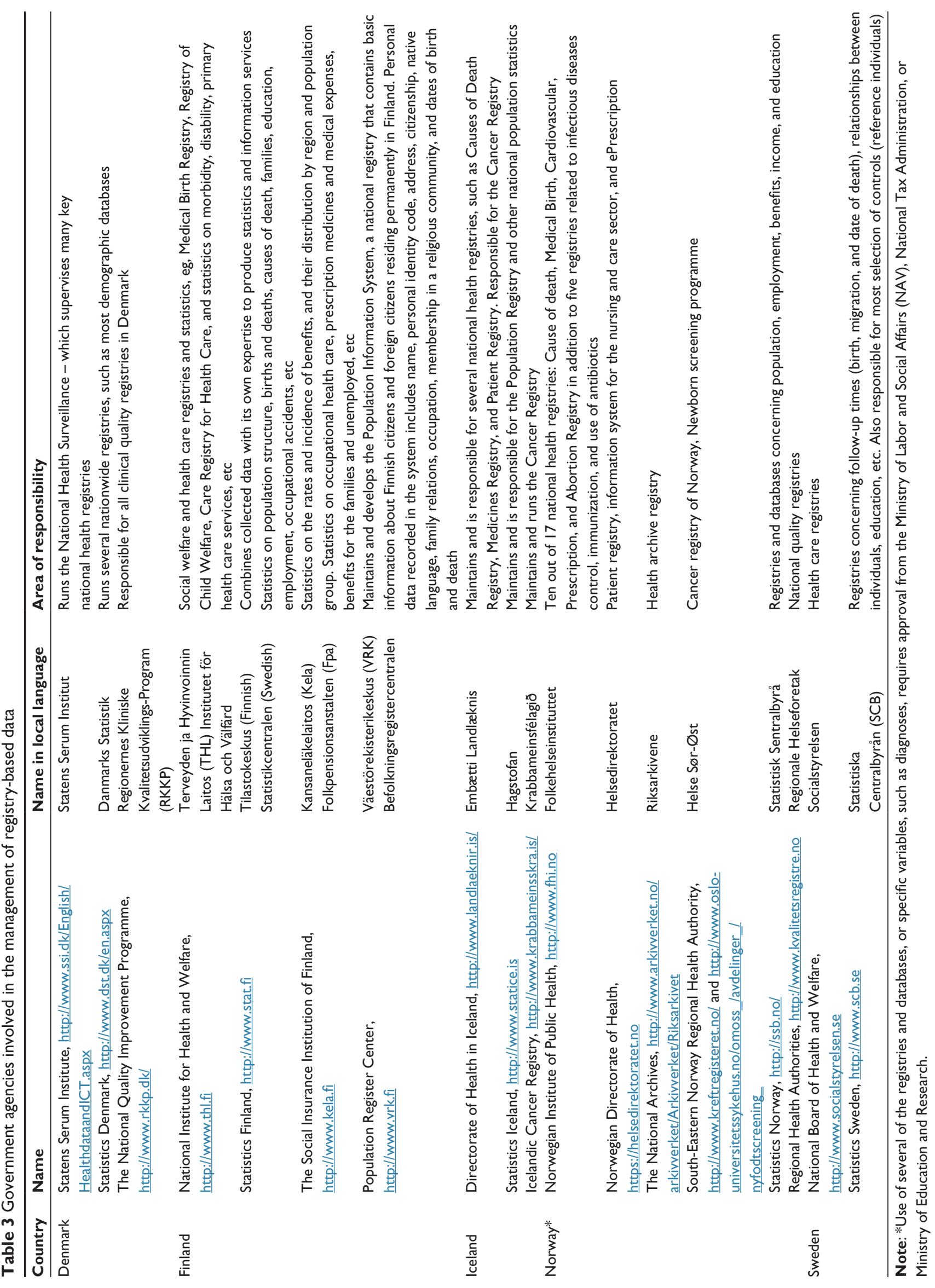


Protection Authority, and the central National Bioethics Committee (the EC) in Iceland.

The establishment of a biobank in Denmark requires approval either by the Danish Data Protection Agency if data are stored for future use only, or by the EC if the biological data are to be used in the specific project. According to the guidelines from the Danish Data Protection Agency, a biobank is considered a manual register. Where material from existing biobanks is used, the research projects are categorized as projects that include human biological material, and thus require approval from the EC. This includes both biobanks previously established for research purposes and clinical biobanks that are set up in connection with a person's contact with the health service for clinical purposes, such as prevention, diagnostics, treatment, or care.

\section{Earlier experience of the researcher}

Furthermore, the EC requests researchers to describe their prior experience with registry-based research (for instance, Swedish ECs require that at least one of the participating researchers has a $\mathrm{PhD}$ degree). Relevant information entered into the EA may include a list of earlier EAs, earlier projects with a similar design, and experience of statistical elaboration of national health care data. Some researchers will also describe their clinical experience of the disorders specified in the EA $1 .^{20}$

\section{Risks and benefits of the research project}

Registry-based research involves no invasive procedures, and the imposed risks on the study participants are few (Table 4) but do include the risk of breaching the participants' integrity (when personal identity data are mismanaged and accessed by non-researchers, or presented at a very detailed level with very few persons in each stratum). Finally, political misuse of data may also occur. To minimize this risk, appropriate storage of data is necessary, and any key file should be stored away from the dataset used for statistical analyses. It is also necessary to state that extra care will be taken to reduce the potential risk of backward identification of individuals that could be based on combining detailed data. Meanwhile, it may seem like a paradox that while there is a strict framework surrounding medical registry-based research, many people seem willing to share their health data through the Internet or social media.

The benefits of using registry data are several: 1) there is no need to contact study participants; 2) large and unbiased study populations are available; and 3) data collection to the different registries is done independently, which minimizes bias in data collection. For instance, several research teams $\mathrm{s}^{21-23}$ have shown

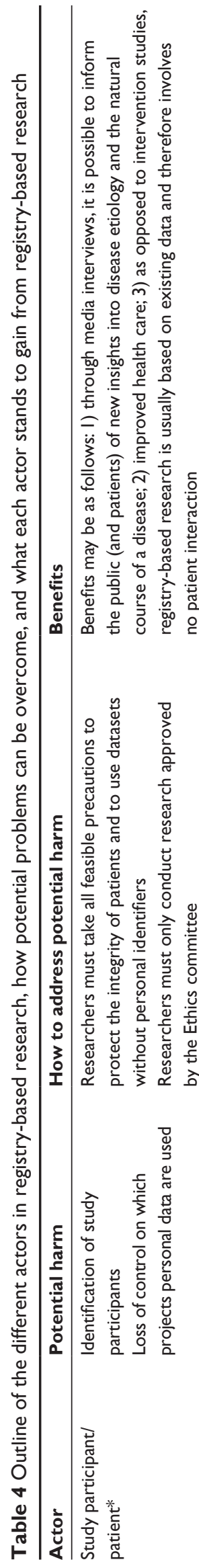

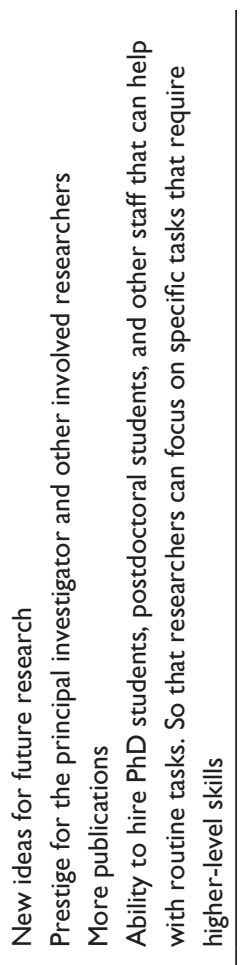

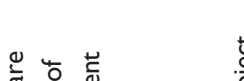

苞苛

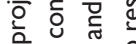

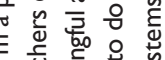
竞 言

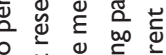

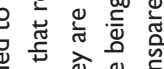

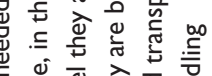

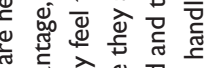

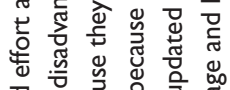

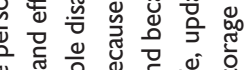

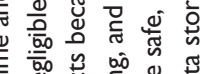

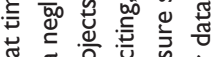

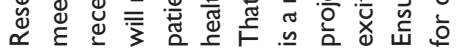
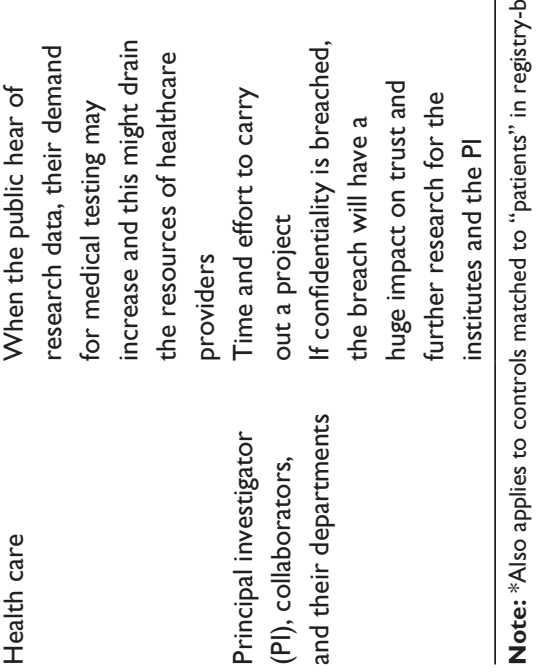
substantial selection bias when applying opt-in procedures in medical research; however, reasons for opting out may not constitute antipathy to research, but rather a misperception among the potential research subjects that their medical data are unlikely to benefit research, ${ }^{24}$ or an unawareness of the balance between scientific losses and confidentiality gains. ${ }^{25}$

Some research questions cannot be addressed in studies other than registry-based studies; for example, studies regarding safety of prenatal exposures, which are not ethical to perform as randomized trials, or studies with great public health interest for which it is difficult or unethical to recruit representative study populations, such as studies of suicide, mental illness, or drug use must be done as registry-based studies. Also, studies with long time follow-up, eg, cancer development or cardiovascular disease after drug exposure, require information reliably collected through registries.

\section{Recruitment of study participants and informed consent}

Recruitment of study participants, whether through contact between a physician and a patient, from contact during earlier studies, or from national registries (without contact with the patient) must be described in the EA. The researchers must argue their reasoning if they choose to exclude vulnerable individuals from the study. Researchers may also choose to underline that all population groups are actually included (to underscore that their study will also benefit a vulnerable population). ${ }^{26}$

An essential part of the EA concerns informed consent. ${ }^{27}$ Although informed consent is crucial in intervention studies to preserve the confidence of the public, it is generally not required for large-scale, registry-based studies in the Nordic countries. Instead, it is assumed that the study participants do not object to registry-based research, provided that such research is deemed ethical by the EC. This assumed agreement to contribute personal data to research is part of the informal contract between the individual and the state (or where relevant, county councils or other suppliers of health care), given that health care is traditionally virtually free of charge (costs are covered through the tax bill). Registry-based data are maintained for the purpose of health care quality improvement and national statistics and are used in economic administration systems, and transfer of data is sometimes an integrated part of the reimbursement system (single individuals cannot opt out; instead, participation is compulsory).

For studies in which the researcher contacts the study participants and informed consent is relevant (eg, in case of linkages with individual questionnaires or biological data), the
EA should include information on who informs the study participants of the study. A written copy of the study information should be attached to the EA, including data on when and how informed consent is collected. This is particularly important when children or individuals with reduced cognitive abilities participate. In Denmark, researchers must provide arguments as to why studies using minors and other legally incompetent persons cannot recruit legally competent persons. Moreover, when processing an application for a study using minors, Danish ECs must consult an expert in pediatrics.

In registry-based research, researchers rarely request informed consent from individual study participants, because recent data suggest that such requirements lead to severe selection bias in large-scale observational research. The arguments that informed consent is not needed for large-scale, registry-based studies in the Nordic countries include: 1) it would render many research proposals impossible because of the sheer number of study participants (sometimes more than 1 million participants); 2) requesting individual approvals would dramatically reduce participation rates and statistical power of most nationwide population-based studies, which is a threat to the scientific validity of the study; 3 ) there is a risk that consent would be especially difficult to obtain in high-risk groups in which positive outcomes are most frequent (selection bias $^{28}$ ), such as in children and in immigrants with limited knowledge of the Nordic languages; 4) some individuals with registry-based information will be dead at the time the study is conducted, and thus, consent cannot be obtained; and 5) the costs of obtaining the consent of millions of individuals with health data would be exorbitant and would prohibit most large-scale research. These arguments conflict with the principles of justice and equality, which stipulate that individuals should not be discriminated against because of an inability to consent. Another feature of ECs in the Nordic countries is that they are generally acknowledged to represent the public, and that approval from the EC can largely replace individual approvals from study participants in registry-based research.

\section{Publication of data}

Finally, the EA requests information about how research data will be made public (generally through presentations at meetings and through scientific manuscripts), and whether the data elaboration/statistical analyses are funded by, for instance, the pharmaceutical industry (and their influence on the research strategies). In addition, other economic relationships should be presented in the EA. Publication of data must guarantee the anonymity of individual patients, and data should be 
presented in aggregated form to eliminate the possibility of recognizing or identifying a specific person. ${ }^{29}$

\section{Attachments to the EA}

Table 5 lists documents that may be required at EA submission. For clinical trial research, further documents may be relevant.

\section{Safeguarding integrity and protecting vulnerable subjects}

While it may seem evident that study participants have much to gain from registry-based research, they may experience considerable loss if integrity is breached. This gain/loss relationship also holds for the individual researcher, responsible research institutions, and registry owners. Table 4 is an outline of the different actors in registry-based research, how potential problems can be overcome, and what each actor stands to gain from registry-based research.

\section{Protection of personal data}

The Swedish, ${ }^{30}$ Danish, ${ }^{31}$ and Icelandic Personal Data Acts classify personal data into sensitive and non-sensitive categories. ${ }^{32}$ All data on political and religious affiliations, as well as medical data, are classified as sensitive. All these data are "sensitive", but some data (eg, data about sexual health) may be regarded as highly sensitive (we use the phrase highly sensitive here, though it is not defined in law).

Table 5 Attachments to the EA

Research plan (and when possible, information for laypersons) (DEN;\# FIN;:" ISL;; NOR;; SWE\#)

Curriculum vitae for the responsible researcher (DEN;\# FIN;\# ISL; NOR;" SWE")

Certificate from the head of the department that a workplace is available for the researcher (DEN;§ FIN;§ISL; NOR;§ SWE\#)

List of participating researchers (DEN;" FIN;" ISL;" NOR;; SWE*)

Advertising material for recruitment of study participants (DEN;" FIN;"

ISL;* NOR;\# SWE*)

Written study information when informed consent is relevant (DEN;\# FIN; ; ISL; NOR;" SWE*)

Copy of the questionnaire or survey if used in the study (DEN;" FIN; ${ }^{*}$ ISL;" NOR;; SWE*)

Description of economic compensation to study participants (DEN;\# FIN; ; ISL;* NOR;; SWE*)

Copy of contracts if the researcher is hired by a funder (DEN;* FIN; ISL;* NOR;* SWE*)

Notes: *Documents may be submitted as part of the EA; \#documents must always

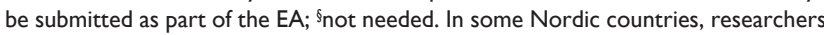
must also submit their own evaluation of ethical dilemmas involved in the project, plus a description of the registry/registries used.

Abbreviations: DEN, Denmark; FIN, Finland; ISL, Iceland; NOR, Norway; SWE, Sweden.
All archived data (ie, from surveys and blood samples) are held as strictly confidential. Relevant safety precautions, including firewalls, inhibit access from unknown users. Thus, only authorized researchers and database personnel have access to such data.

Despite safeguards, registry-based research still carries a small risk for breach of confidentiality (Table 4). However, in practice, such breaches have occurred only very rarely in the Nordic countries. A recent Nordic joint report described a research project involving individuals with mental illness in which patients had received an e-mail with e-mail addresses to all patients openly listed, and researchers breaching integrity by including personal data on cancer on PowerPoint slides for a public meeting. ${ }^{33}$

\section{Personal data officer}

In Sweden, storage of personal research data must also be approved by a personal data officer (Swedish language, "Personuppgiftsombud"). The Swedish personal data officer is a function rather than an individual role. The idea is that the public should know whom to contact in case they have questions. Some research bodies have a personal data officer that ensures that personal data are managed according to national laws. In this sense, the data officer is similar to an accountant, although the latter is responsible for financial transactions, whereas the former is responsible for personal data.

In Norway, a personal data officer (Norwegian language, "Personvernombud") is a function that institutes and businesses may choose to engage. The personal data officer is administered by the Data Inspectorate and approves notifications of use and storage of personal data, while the Datainspektion must provide a license when this is needed.

In Finland, a registry notification (including a registry description of the person registered) needs to be made to the Data Protection Ombudsman only in registry-based research when processing automated, sensitive personal data directly from registries, not from the individual and without his/her consent. In research where all participants have given their informed consent on data collection, no registry notification needs to be made. Also, when applying for data from national health care registries, the registry authority consults the data protection ombudsman. In Finland, the Office of the data protection ombudsman is an independent authority operating in conjunction with the Ministry of Justice. The office is run by the data protection ombudsman, who is appointed by the Council of State for a term of 5 years.

The Data Protection Authority (local language, "Persónuvernd") in Iceland is an independent authority 
operating in conjunction with the Ministry of Internal Affairs, which implements acts on the protection of privacy and processes personal data, and conducts audits on the security of personal data. ECs in Iceland must report all received EAs to the Data Protection Authority and must obtain approval for the use and handling of personal data by researchers.

Denmark has no personal data officer system, but the Data Protection Authority there conducts audits on the security of storage and use of personal data.

\section{Vulnerability and children}

Vulnerability refers to the inability of individuals to protect themselves from harm. Almost all registry-based research will involve vulnerable individuals. Traditionally, vulnerability has not been considered in medical research, ${ }^{34,35}$ and existing EA guidelines from such establishments as the Swedish ECs only consider vulnerability indirectly, and therefore, urge researchers to consider the special circumstances related to children or individuals with limited decision skills. Other categories of vulnerable individuals include people with psychiatric disabilities and the homeless.

Knowledge about how vulnerable individuals experience research is scarce, but it seems that they generally have a positive experiences of research; however, a minority of these persons $^{36}$ have experienced some form of distress. Among vulnerable patients participating in registry-based research are the very sick and sometimes unconscious patients. These patients, however, only participate indirectly in that their health care data are stored in the national registries outlined in Table S1 to the same extent as that of all other Nordic individuals seeking health care. Neither these nor other patients are usually contacted or asked to participate in registry-based research; instead, their interests are represented by the EC.

Registry-based research generally includes children when 1) they have seen a physician/been admitted to hospital, developed cancer, or given birth before the age of 18 years (or are selected as age-matched controls); 2) they are children to a father or mother in need of health care (if the research involves several generations); 3 ) they have a brother or sister who has been treated in the health care system (and sibling analyses are performed); or 4) they have received a dispensed drug (registered in a prescribed drug register).

\section{Re-use of data already delivered to researchers}

Re-use of existing data is usually cost-effective, decreases the need for additional data storage, and reduces the risk of data security breaches (when data are sent from government agencies to researchers). Re-use of data should preferably be consistent with the aim of the original study. The Nordic countries differ with regard to the stipulated need for new EAs before re-use of data. In Denmark and Finland, data can be re-used by the researcher without further addendum if the original approval from the data protection agency has not expired and if the new analyses are all within the field covered by this approval. Similar rules apply in Sweden and Iceland, although researchers from these countries are expected to submit an amendment to the EC, arguing why re-use of data is necessary. In Norway, a fully new EA is needed for the re-use of existing data for a different purpose.

\section{Discussion}

Over time, medical research has moved from descriptions of individual patients to applied statistics, ${ }^{37}$ and ever since the landmark studies of Doll and Hill, ${ }^{38,39}$ numerical follow-up has become more and more important in research; today, numerical follow-up is the hallmark of modern medicine.

The potential of Nordic registry research is formidable, as these countries have national health data sources and the possibility to combine data in a way not possible in other countries (Table 6). There is a growing interest in using and combining Nordic registries in research; however, today's system for collecting and combining data within and between the Nordic countries is discouraging and limits use of these resources. Common Nordic registry and epidemiology research meet many national obstacles when doing trans-Nordic research (NORIA-net on Registries). ${ }^{40}$ The problem of cross-border access in sharing sensitive individual medical information is the same whether it involves collaboration between national statistical agencies or between Nordic clinical researchers. The same holds for biobanks and tissue sampling, ie, existing national legislations in the Nordic countries make it difficult or impossible for a free exchange of sample and tissue information between researchers in the Nordic countries. Further, for clinical interventional studies (eg, new treatments), different legislation and policies are not conducive to working on a common Nordic ground.

In addition to the cross-border issues in sharing registry data, today's systems for obtaining approvals and eventually data in several of the Nordic countries are extremely slow and complicated, with numerous applications and approvals from data owners in addition to the mandatory ethical and data inspectorate approval. It often takes several years of EA submissions until data are available for statistical analysis. The time spent coordinating approvals and obtaining data for Nordic collaboration is therefore extensive for each project. 
Table 6 Examples of Nordic registry-based studies

\begin{tabular}{|c|c|}
\hline Etiology & Article title \\
\hline Lange et $\mathrm{al}^{50}$ & Lung-function trajectories leading to chronic obstructive pulmonary disease \\
\hline Larsson and Wolk ${ }^{51}$ & Dietary fiber intake is inversely associated with stroke incidence in healthy Swedish adults \\
\hline Bolinder et $\mathrm{al}^{52}$ & Smokeless tobacco use and increased cardiovascular mortality among Swedish construction workers \\
\hline Naess et $\mathrm{al}^{53}$ & Cardiovascular mortality in relation to birth weight of children and grandchildren in 500,000 Norwegian families \\
\hline \multicolumn{2}{|r|}{ P } \\
\hline Granlund et $\mathrm{al}^{54}$ & Diverticular disease and the risk of colon cancer - a population-based case-control study \\
\hline Cantarutti et al $^{55}$ & Body mass index and mortality in men with prostate cancer \\
\hline Holm et $\mathrm{al}^{56}$ & $\begin{array}{l}\text { Pre-diagnostic alcohol consumption and breast cancer recurrence and mortality: results from a prospective cohort } \\
\text { with a wide range of variation in alcohol intake }\end{array}$ \\
\hline Kristinsson et $\mathrm{al}^{57}$ & $\begin{array}{l}\text { Patterns of survival in lymphoplasmacytic lymphoma/Waldenström macroglobulinemia: a population-based study of } \\
\text { I,555 patients diagnosed in Sweden from } 1980 \text { to } 2005\end{array}$ \\
\hline Román et $\mathrm{al}^{58}$ & Postmenopausal hormone therapy and the risk of breast cancer in Norway \\
\hline \multicolumn{2}{|l|}{ Therapy } \\
\hline Lichtenstein et $\mathrm{al}^{59}$ & Medication for attention deficit-hyperactivity disorder and criminality \\
\hline Madsen et $\mathrm{al}^{60}$ & $\begin{array}{l}\text { Geographic analysis of the variation in the incidence of attention deficit-hyperactivity disorder (ADHD) in a } \\
\text { country with free access to healthcare: a Danish cohort study }\end{array}$ \\
\hline Pasternak and Hviid ${ }^{61}$ & Use of proton-pump inhibitors in early pregnancy and the risk of birth defects \\
\hline Lund et $\mathrm{al}^{62}$ & Prescription drug use among pregnant women in opioid maintenance treatment \\
\hline Stephansson et $\mathrm{al}^{44}$ & Selective serotonin reuptake inhibitors during pregnancy and risk of stillbirth and infant mortality \\
\hline \multicolumn{2}{|l|}{ Quality assessment } \\
\hline Vestergaard et $\mathrm{al}^{63}$ & Geographical variation in use of intensive care: a nationwide study \\
\hline Kristiansen et $\mathrm{al}^{64}$ & Off-hours admission and acute stroke care quality: a nationwide study of performance measures and case-fatality \\
\hline
\end{tabular}

In contrast, politicians, registry owners, institutions, and researchers are all promoting and welcoming increased use of registry-based data sources available in the Nordic countries. The public also shares expectations that information collected mandatorily through public registries and systems is used to improve knowledge on health and diseases, and for research purposes. Consequently, there is a need to create a common Nordic research area. The three main areas (registries, biobanks, and interventional research) have in common the idea that when human research is involved, approval by a research EC is compulsory. So far, the discussion on a common Nordic research area has focused on the different legislations between the Nordic countries. We propose that common Nordic denominators for research ethical review must be created. A multinational agreement between the Nordic countries on accepting ethical decisions from another Nordic country in research using human subjects, or mutual recognition, is suggested.

The reasons for the acceptance of ethical decisions made in other Nordic countries are the following: 1) the countries share a history that goes back more than 1,000 years; 2 ) there are large similarities between the countries' ethical review systems; 3) the countries share religious, cultural, and ethical values; 4) the countries have in common a system for social welfare that guarantees respect for the individual; and 5) they share a common democratic allegiance. ${ }^{41}$ They also share a similar approach in how they analyze applications and IRBs are all staffed with laypersons, experts, and lawyers (Table 1). Thus, there are more similarities than differences between the countries regarding the content of the ethical review, even if the procedures vary from country to country.

Implementation of a multinational agreement would greatly reduce resistance to collaborative Nordic clinical research projects and thereby accelerate the process of developing new treatments to improve public health for Nordic citizens and welfare societies. Hence, the main driving force behind increased collaboration and use of Nordic data rather than merely national data should be the needs of the patients. Nordic collaboration in registry-based research has already yielded important results ${ }^{42-45}$ based on the vast array of national registries available in Denmark, Finland, Iceland, Norway, and Sweden (Table S1). For instance, merging data from all Nordic countries allows for studies of rare exposures or outcomes in the large study population of more than 25 million people combined. Other examples of unique Nordic research could be comparing and evaluating differences between the Nordic countries such as policies/ recommendations of medications use, incorporation of new medications, changes in vaccination programs, follow-up programs, etc.

Denmark, Finland, and Sweden are part of the European Union (EU), and will therefore be affected by the proposed EU general data protection regulation. This initiative is an effort by the European Commission to enforce a unified data protection framework for all member states in the EU. ${ }^{46} \mathrm{As}$ members of the European Economic Area (EEA), Norway and Iceland will also most likely be affected by this new 
legislation. The current version of the regulation stipulates that research use of registry-based health care data does not require informed consent from all study participants. Should the next generation of the EU general data protection regulations require individual informed consents, truly population-based studies would no longer be possible in Denmark, Finland or Sweden.

Gillon identifies a number of ethical principles/areas that may be considered in registry-based research. ${ }^{47}$ Pros and cons of research are often summarized in a risk-benefit analysis. Our position is that the benefits of registry-based research to patients as well as to health care in general far outweigh potential liabilities. Safeguarding the integrity of the patient and that of the managing physician is crucial for acceptance by the Nordic health care registries. Misuse of registry-based data for political reasons is rare, but should that happen, data storage at independent universities (where data access is limited to academics) may be preferable to the current status where data are stored with government agencies. However, it should be noted that current regulations in the Nordic countries hinder misuse of data (by researchers, politicians, and others), regardless of where data is stored.

Individuals usually benefit from registry-based research in that the research increases knowledge about the natural history and risk factors associated with their disease. Given that registry-based research does not carry liabilities (physical or non-physical) to the study participants, we argue that research participants stand to gain more than they stand to lose from such research. Closely related to the discussion about the potential benefits of research is the contention that, for reasons of justice and equality, research should also be performed on all population sub-groups, in that exclusions due to such factors as age, sex, race, ethnicity, or country of birth, deprive these groups of relevant data about their diseases, prognoses, disease management, and follow-up treatment options.

In recent years, medical quality registries have become an important source of data in registry-based research. ${ }^{48}$ Quality registries usually focus on a specific diagnosis (eg, prostate cancer $^{49}$ ). As opposed to most national registries in the Nordic countries, participants in Swedish quality registries can choose not to participate. Research projects emanating from quality registries must undergo the same stringent assessment by the EC as other registry-based studies.

\section{Conclusion}

In conclusion, prevailing conditions for registry-based research are comparable in the Nordic countries, and researchers from these countries face similar issues. Although there are differences in the composition of ECs and the content of EAs, we feel that these differences can be bridged and dealt with positively with increasing collaboration and more high-quality research as ultimate goals.

\section{Disclosure}

PL was employed by the Stockholm Regional Ethical Review Board at the time of writing this manuscript. The authors report no other conflicts of interest in this work.

\section{References}

1. Anell A. The public-private pendulum - patient choice and equity in Sweden. N Engl J Med. 2015;372(1):1-4.

2. Kettis-Lindblad A, Ring L, Viberth E, Hansson MG. Perceptions of potential donors in the Swedish public towards information and consent procedures in relation to use of human tissue samples in biobanks: a population-based study. Scand J Public Health. 2007;35(2):148-156.

3. Schmidt M, Pedersen L, Sørensen HT. The Danish Civil Registration System as a tool in epidemiology. Eur J Epidemiol. 2014;29(8): 541-549.

4. Ludvigsson JF, Otterblad-Olausson P, Pettersson BU, Ekbom A. The Swedish personal identity number: possibilities and pitfalls in healthcare and medical research. Eur J Epidemiol. 2009;24(11):659-667.

5. Hemminki K, Li X, Sundquist J, Sundquist K. Familial association between type 1 diabetes and other autoimmune and related diseases. Diabetologia. 2009;52(9):1820-1828.

6. Skjaerven R, Vatten LJ, Wilcox AJ, Rønning T, Irgens LM, Lie RT. Recurrence of pre-eclampsia across generations: exploring fetal and maternal genetic components in a population based cohort. BMJ. 2005;331(7521):877.

7. Bonamy AK, Parikh NI, Cnattingius S, Ludvigsson JF, Ingelsson E. Birth characteristics and subsequent risks of maternal cardiovascular disease: effects of gestational age and fetal growth. Circulation. 2011;124(25):2839-2846.

8. Bakken IJ, Revdal E, Nesvåg R, et al. Substance use disorders and psychotic disorders in epilepsy: a population-based registry study. Epilepsy Res. 2014;108(8):1435-1443.

9. Håberg SE, Trogstad L, Gunnes N, et al. Risk of fetal death after pandemic influenza virus infection or vaccination. $N$ Engl J Med. 2013;368(4):333-340.

10. Centrala etikprövningsnämnden - Central ethical review board annual report 2014 [homepage on the Internet]. Available from: http://www. epn.se/media/2100/cepns-aarsredovisning-2014.pdf. Accessed October $15,2015$.

11. Centrala etikprövningsnämnden - Central ethical review board-supervision. [homepage on the Internet]. Available from: http://www.epn.se/ centrala-etikproevningsnaemnden/cepns-tillsyn/. Accessed October 15, 2015.

12. Finnish National Committee on Medical Research Ethics [webpage on the Internet]. Helsinki, Finland: Finnish National Committee on Medical Research Ethics; 2015. Available from: http://tukija.fi/en. Accessed September 25, 2015.

13. Vísindasiðanefnd (Bioethics) [homepage on the Internet]. Available from: www.vsn.is. Accessed October 15, 2015.

14. US department of Health \& Human Services: Institution Review Boards [homepage on the Internet]. Available from: http:/www.hhs.gov/ohrp/ assurances/irb. Accessed October 15, 2015.

15. Lag om etikprövning av forskning som avser människor. Law about ethical review in human research. [homepage on the Internet]. Available from: http://www.riksdagen.se/sv/Dokument-Lagar/Lagar/ Svenskforfattningssamling/Lag-2003460-om-etikprovning_sfs-2003460/. Accessed October 15, 2015. 
16. The Hospital District of Helsinki and Uusimaa [webpage on the Internet]. Finnish ethics application. Helsinki, Finland: The Hospital District of Helsinki and Uusimaa; 2015. Available from: http://www. hus.fi/tutkijalle/eettiset-toimikunnat/ohjeet-ja-hakemuslomakkeet/ Sivut/default.aspx. Accessed May 22, 2015. Finnish.

17. Vísindasiðanefnd (Bioethics) - License for ethical approval [webpage on the Internet]. Available from: http://www.vsn.is/is/content/leyfisskylda. Accessed October 15, 2015.

18. Danish ethical review board. Guidelines about Notification etc. of a Biomedical Research Project to the Committee System on Biomedical Research Ethics, No 9154, 5 May 2011 [webpage on the Internet]. Available from: http://www.dnvk.dk/English/guidelinesaboutnotification.aspx\#AFSNIT 2.0. Accessed October 15,2015.

19. Etikprövningsnämnderna. Ethical review boards. Application [webpage on the Internet]. Available from: http://www.epn.se/start/ansoekan/. Accessed October 15, 2015.

20. Swedish ethical review boards: Application form [webpage on the Internet]. Available from: www.epn.se/media/1023/ansoekningsblankett.doc Accessed October 15, 2015.

21. Trevena L, Irwig L, Barratt A. Impact of privacy legislation on the number and characteristics of people who are recruited for research: a randomised controlled trial. J Med Ethics. 2006;32(8):473-477.

22. Woolf SH, Rothemich SF, Johnson RE, Marsland DW. Selection bias from requiring patients to give consent to examine data for health services research. Arch Fam Med.2000;9(10):1111-1118.

23. Junghans C, Feder G, Hemingway H, Timmis A, Jones M. Recruiting patients to medical research: double blind randomised trial of "opt-in" versus “opt-out" strategies. BMJ. 2005;331(7522):940.

24. Crombie IK, McMurdo ME, Irvine L, Williams B. Overcoming barriers to recruitment in health research: concerns of potential participants need to be dealt with. BMJ. 2006;333(7564):398.

25. Hewison J, Haines A. Overcoming barriers to recruitment in health research. BMJ. 2006;333(7562):300-302.

26. Swedish ethical review boards: Application form [webpage on the Internet]. Available from: www.epn.se/media/1023/ansoekningsblankett.doc. Accessed October 15, 2015.

27. World Health Organization Research Ethics Review Committee [webpage on the Internet]. The Process of Obtaining Informed Consent Geneva, Switzerland: World Health Organization; 2015. Available from: http://www.who.int/rpc/research_ethics/Process_seeking_IF_printing. pdf. Accessed May 25, 2015.

28. Kho ME, Duffett M, Willison DJ, Cook DJ, Brouwers MC. Written informed consent and selection bias in observational studies using medical records: systematic review. BMJ. 2009;338:b866.

29. Swedish ethical review boards: Application form [webpage on the Internet]. Available from: www.epn.se/media/1023/ansoekningsblankett.doc. Accessed October 15, 2015.

30. The Swedish data inspection board: The personal data act [webpage on the Internet]. Available from: http://www.datainspektionen.se/ in-english/legislation/the-personal-data-act/. Accessed October 15, 2015.

31. Datatilsynet. The Danish data inspection board: Compiled version of the act on processing of personal data [webpage on the Internet]. Available from: $\mathrm{http}: / / / \mathrm{www}$.datatilsynet.dk/english/the-act-on-processing-of-personaldata/read-the-act-on-processing-of-personal-data/compiled-version-ofthe-act-on-processing-of-personal-data/. Accessed October 15, 2015.

32. The Icelandic Data Protection Act [webpage on the Internet]. Available from: http://www.personuvernd.is/information-in-english/greinar/ nr/438. Accessed October 15, 2015.

33. Joint Nordic Registers and Biobanks - a goldmine for health and welfare research [webpage on the Internet]. Available from: http://www. nordforsk.org/en/publications/publications_container/joint-nordicregisters-and-biobanks-a-goldmine-for-health-and-welfare-research. Accessed October 15, 2015.

34. Silverman HJ, Druml C, Lemaire F, Nelson R; European Union Directive. The European Union Directive and the protection of incapacitated subjects in research: an ethical analysis. Intensive Care Med. 2004;30(9):1723-1729.
35. Liddell $\mathrm{K}$, Bion J, Chamberlain D, et al. Medical research involving incapacitated adults: implications of the EU Clinical Trials Directive 2001/20/EC. Med Law Rev. 2006;14(3):367-417.

36. Gysels MH, Evans C, Higginson IJ. Patient, caregiver, health professional and researcher views and experiences of participating in research at the end of life: a critical interpretive synthesis of the literature. $B M C$ Med Res Methodol. 2012;12:123.

37. [No authors listed]. Looking back on the millennium in medicine. N Engl J Med. 2000;342(1):42-49.

38. Doll R, Hill AB. Smoking and carcinoma of the lung; preliminary report. Br Med J. 1950;2(4682):739-748.

39. Doll R, Hill AB. The mortality of doctors in relation to their smoking habits; a preliminary report. $\mathrm{Br}$ Med $J$. 1954;1(4877):1451-1455.

40. Nordforsk [homepage on the Internet]. Available from: http://www. nordforsk.org. Accessed October 15, 2015.

41. Nordic Trial Alliance [homepage on the Internet]. Oslo, Norway: The Nordic Council of Ministers and NordForsk; 2015. Available from: http://nta.nordforsk.org. Accessed October 5, 2015.

42. Lichtenstein P, Holm NV, Verkasalo PK, et al. Environmental and heritable factors in the causation of cancer - analyses of cohorts of twins from Sweden, Denmark, and Finland. N Engl J Med. 2000;343(2):78-85.

43. Furu K, Kieler H, Haglund B, et al. Selective serotonin reuptake inhibitors and venlafaxine in early pregnancy and risk of birth defects: population based cohort study and sibling design. BMJ. 2015;350:h1798.

44. Stephansson O, Kieler H, Haglund B, et al. Selective serotonin reuptake inhibitors during pregnancy and risk of stillbirth and infant mortality. JAMA. 2013;309(1):48-54.

45. Sandin S, Schendel D, Magnusson P, et al. Autism risk associated with parental age and with increasing difference in age between the parents. Mol Psychiatry. Epub 2015 Jun 9.

46. Nyrén O, Stenbeck M, Grönberg H. The European Parliament proposal for the new EU General Data Protection Regulation may severely restrict European epidemiological research. Eur J Epidemiol. 2014;29(4):227-230.

47. Gillon R. Medical ethics: four principles plus attention to scope. $B M J$. 1994;309(6948):184-188.

48. Emilsson L, Lindahl B, Koster M, Lambe M, Ludvigsson JF. Review of 103 Swedish Healthcare Quality Registries. J Intern Med. 2015;277(1):94-136.

49. Van Hemelrijck M, Wigertz A, Sandin F, et al; NPCR and PCBaSe Sweden. Cohort profile: the National Prostate Cancer Register of Sweden and Prostate Cancer data Base Sweden 2.0. Int J Epidemiol. 2013;42(4):956-967.

50. Lange P, Celli B, Agustí A, et al. Lung-function trajectories leading to chronic obstructive pulmonary disease. $N$ Engl J Med. 2015;373(2): 111-122.

51. Larsson SC, Wolk A. Dietary fiber intake is inversely associated with stroke incidence in healthy Swedish adults. J Nutr. 2014;144(12): 1952-1955.

52. Bolinder G, Alfredsson L, Englund A, de Faire U. Smokeless tobacco use and increased cardiovascular mortality among Swedish construction workers. Am J Public Health. 1994;84(3):399-404.

53. Naess O, Stoltenberg C, Hoff DA, et al. Cardiovascular mortality in relation to birth weight of children and grandchildren in 500,000 Norwegian families. Eur Heart J. 2013;34(44):3427-3436.

54. Granlund J, Svensson T, Granath F, et al. Diverticular disease and the risk of colon cancer - a population-based case-control study. Aliment Pharmacol Ther. 2011;34(6):675-681.

55. Cantarutti A, Bonn SE, Adami HO, Grönberg H, Bellocco R, Bälter K. Body mass index and mortality in men with prostate cancer. Prostate. 2015;75(11):1129-1136.

56. Holm M, Olsen A, Christensen J, et al. Pre-diagnostic alcohol consumption and breast cancer recurrence and mortality: results from a prospective cohort with a wide range of variation in alcohol intake. Int J Cancer. 2013;132(3):686-694.

57. Kristinsson SY, Eloranta S, Dickman PW, et al. Patterns of survival in lymphoplasmacytic lymphoma/Waldenström macroglobulinemia: a population-based study of 1,555 patients diagnosed in Sweden from 1980 to 2005. Am J Hematol. 2013;88(1):60-65. 
58. Román M, Sakshaug S, Graff-Iversen S, et al. Postmenopausal hormone therapy and the risk of breast cancer in Norway. Int $J$ Cancer. Epub 2015 Aug 20.

59. Lichtenstein P, Halldner L, Zetterqvist J, et al. Medication for attention deficit-hyperactivity disorder and criminality. $N$ Engl J Med. 2012;367(21):2006-2014.

60. Madsen KB, Ersbøll AK, Olsen J, Parner E, Obel C. Geographic analysis of the variation in the incidence of ADHD in a country with free access to healthcare: a Danish cohort study. Int J Health Geogr. 2015;14(1):24.

61. Pasternak B, Hviid A. Use of proton-pump inhibitors in early pregnancy and the risk of birth defects. N Engl J Med. 2010;363(22):2114-2123.

62. Lund IO, Skurtveit S, Engeland A, Furu K, Ravndal E, Handal M. Prescription drug use among pregnant women in opioid maintenance treatment. Addiction. 2013;108(2):367-376.

63. Vestergaard AH, Christiansen CF, Nielsen H, Christensen S, Johnsen SP. Geographical variation in use of intensive care: a nationwide study. Intensive Care Med. Epub 2015 Aug 4.

64. Kristiansen NS, Mainz J, Nørgård BM, Bartels PD, Andersen G, Johnsen SP. Off-hours admission and acute stroke care quality: a nationwide study of performance measures and case-fatality. Stroke. 2014;45(12):3663-3669.

65. Andersen TF, Madsen M, Jørgensen J, Mellemkjoer L, Olsen JH. The Danish National Hospital Register. A valuable source of data for modern health sciences. Dan Med Bull. 1999;46(3):263-268.

66. Knudsen LB, Olsen J. The Danish Medical Birth Registry. Dan Med Bull. 1998;45(3):320-323.

67. Storm HH, Michelsen EV, Clemmensen IH, Pihl J. The Danish Cancer Registry - history, content, quality and use. Dan Med Bull. 1997;44(5):535-539.
68. Gjerstorff ML. The Danish Cancer Registry. Scand J Public Health. 2011;39(7 Suppl):42-45.

69. Munk-Jørgensen P, Mortensen PB. The Danish Psychiatric Central Register. Dan Med Bull. 1997;44(1):82-84.

70. Ludvigsson JF, Andersson E, Ekbom A, et al. External review and validation of the Swedish national inpatient register. BMC Public Health. 2011;11:450.

71. de Faire U, Friberg L, Lorich U, Lundman T. A validation of cause-of-death certification in 1,156 deaths. Acta Med Scand. 1976;200(3):223-228.

72. Johansson LA, Westerling R. Comparing Swedish hospital discharge records with death certificates: implications for mortality statistics. Int J Epidemiol. 2000;29(3):495-502.

73. Barlow L, Westergren K, Holmberg L, Talbäck M. The completeness of the Swedish Cancer Register: a sample survey for year 1998. Acta Oncol. 2009;48(1):27-33.

74. Mattsson B, Wallgren A. Completeness of the Swedish Cancer Register. Non-notified cancer cases recorded on death certificates in 1978. Acta Radiol Oncol. 1984;23(5):305-313.

75. Wettermark B, Hammar N, Fored CM, et al. The new Swedish Prescribed Drug Register - opportunities for pharmacoepidemiological research and experience from the first six months. Pharmacoepidemiol Drug Saf. 2007;16(7):726-735.

76. World Health Organization. International classification of diseases for oncology (ICD-O): Third edition, First revision. Geneva: World Health Organization; 2013. Available from: http://apps.who.int/iris/bitstream /10665/96612/1/9789241548496_eng.pdf?ua=2. Accessed September 29, 2015. 


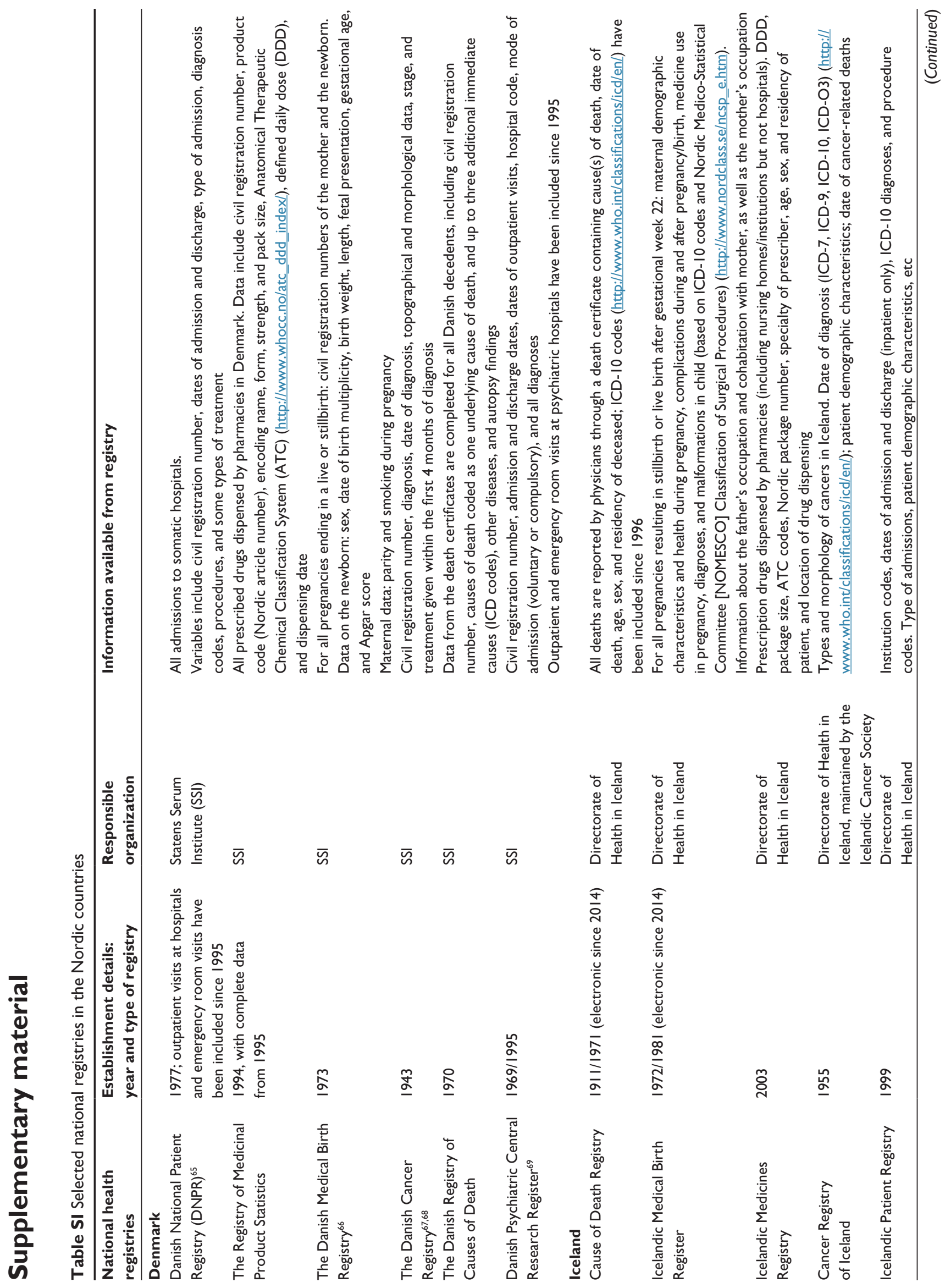




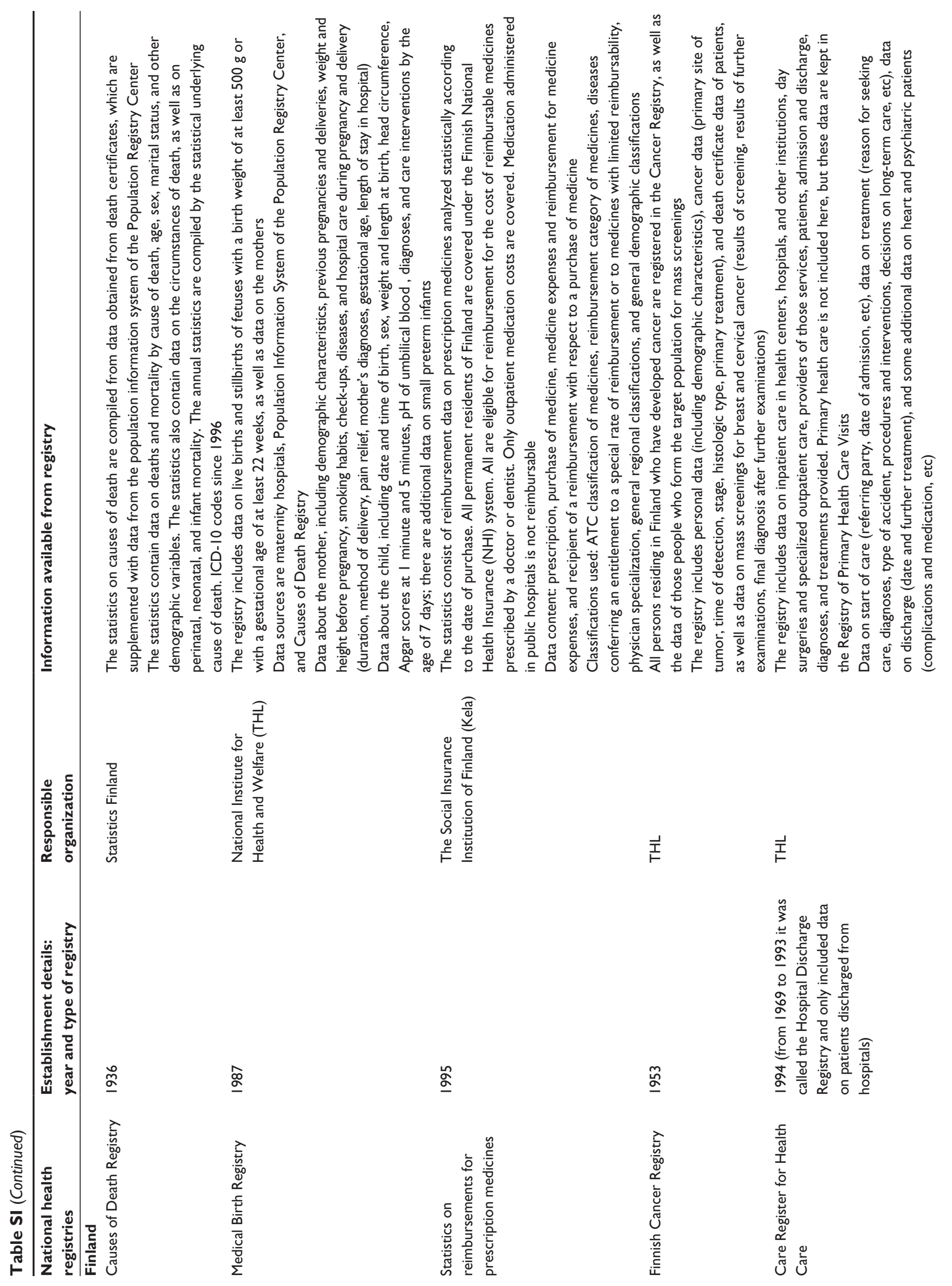



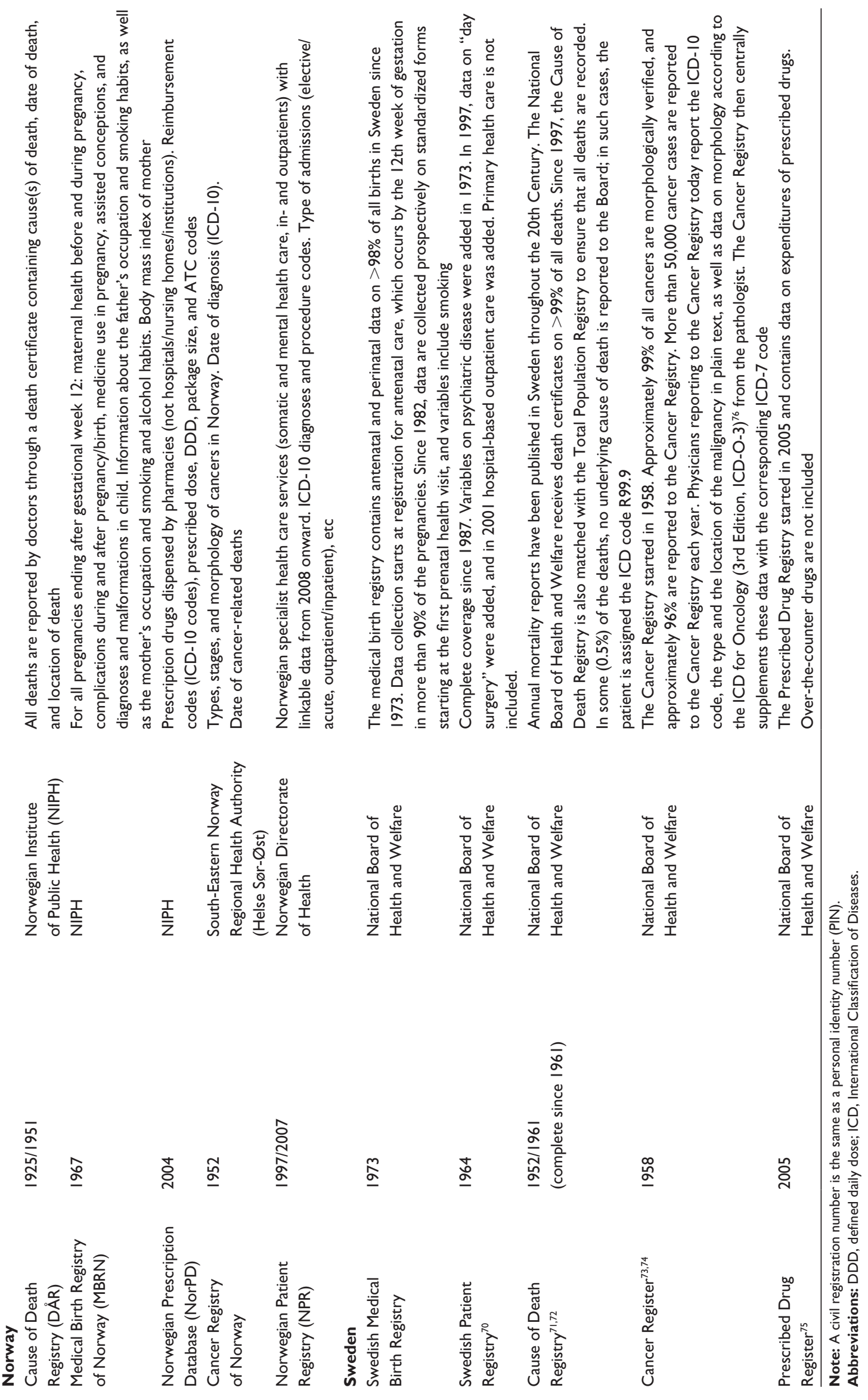


\section{Publish your work in this journal}

Clinical Epidemiology is an international, peer-reviewed, open access, online journal focusing on disease and drug epidemiology, identification of risk factors and screening procedures to develop optimal preventative initiatives and programs. Specific topics include: diagnosis, prognosis, treatment, screening, prevention, risk factor modification,

Submit your manuscript here: http://www.dovepress.com/clinical-epidemiology-journal systematic reviews, risk \& safety of medical interventions, epidemiology \& biostatistical methods, and evaluation of guidelines, translational medicine, health policies \& economic evaluations. The manuscript management system is completely online and includes a very quick and fair peer-review system, which is all easy to use. 